\title{
IDENTIFIKASI GUGUS FUNGSI DAN KANDUNGAN MINERAL LEMPUNG PACITAN DENGAN SPEKTROSKOPI INFRA RED (IR) X-RAY DIFFRACTION (XRD)
}

\author{
Pangoloan Soleman \\ Dosen Fakultas Tarbiyah dan Keguruan UIN SUSKA Riau \\ Solemanriau@yahoo.co.id
}

\begin{abstract}
Clay is natural mineral from silicate family like crystal which has approximately 2 micrometer. There are two component unit of atom in clay mineral. One consists of oxygen or hidroksida with alumunium, iron or magnesium that coordinated in octahedral system. Others, it is tetrahedral system from silicon with oxygen or hidroksida. Based on IR analysis, it can be known that metal-OH bending vibrations it can be seen at 912,3 $\mathrm{cm}^{-1}$ wavelength. On the other bands between 694,3 and $754,1 \mathrm{~cm}^{-1}$ that are Si-O bending vibrations. X-Ray Diffraction (X-RD) analysis be seen main peak at $2 \theta=5,70^{\circ}\left(d_{001}=15,48 \AA\right)$ and $2 \theta=20,02^{\circ}\left(d_{001}=4,43 \AA\right)$. That are for smectite mineral kind montmorillonite as main unit in clay from Pacitan
\end{abstract}

Keywords: Lempung, Clay, Montmorillonit, IR, XRD

\section{PENDAHULUAN}

Lempung dapat didefinisikan sebagai campuran partikel-partikel pasir, debu dan bagian-bagian tanah liat yang mempunyai sifatsifat karakteristik yang berlainan dalam ukuran yang kira-kira sama. Salah satu ciri partikelpartikel tanah liat adalah mempunyai muatan ion positif yang dapat dipertukarkan. Material ini mempunyai daya serap dengan berubahnya kadar kelembapan. Tanah liat mempunyai luas permukaan yang sangat besar (Mahida, 1984).

Lempung adalah mineral alam dari keluarga silikat yang berbentuk kristal dengan struktur berlapis berukuran lebih kecil dari 2 mikrometer. Menurut Grim (1968) terdapat dua unit penyusun yang terlibat dalam kisi-kisi atom pada sebagian besar mineral lempung. Satu unit tersusun dari oksigen atau hidroksida dengan alumunium, besi atau magnesium yang terkoordinasi dalam sistem oktahedral. Penggabungan dari unit-unit oktahedral ini dapat membentuk struktur lapis oktahedral seperti terlihat pada gambar 1 . Sedangkan unit pembangun yang lain adalah sistem tetrahedral dari silikon dengan oksigen atau hidroksi. Rangkaian unit-unit tetrahedral ini juga dapat membentuk struktur lapis tetrahedral seperti terlihat pada gambar 2. Diantara lapisan terdapat kation-kation yang berfungsi menyeimbangkan muatan negatif yang ada pada bidang lapisnya.

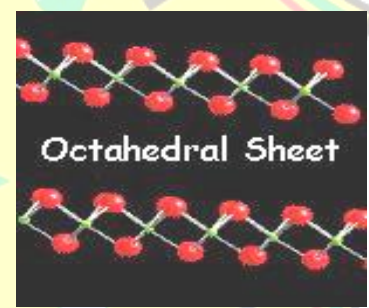

Gambar 1. Lembaran oktahedral

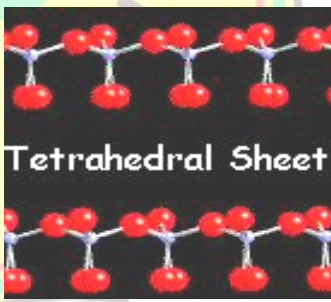

Gambar 2. Lembaran Tetrahedral

Pengelompokan lempung dapat didasarkan atas struktur dan komposisinya (Pinnavaia, 1983). Berdasarkan strukturnya lempung dibagi menjadi 3 golongan yaitu: kristalin (crystalline minerals), amorf (amorphous) dan campuran (mixed layered). Sementara itu mineral kristalin dibedakan menjadi mineral berlapis (layered mineral) dan mineral berserabut (fibrous minerals). Menurut Theng (1977), berdasarkan perbandingan struktur tetrahedral dan 
oktahedralnya, mineral berlapis dibedakan menjadi 3 yaitu: (1). mineral tipe 1:1, mineral yang terdiri dari satu lapisan oktahedral dan satu lapisan tetrahedral, misalnya kaolin dan sepentin, (2). mineral tipe 2:1, mineral yang terdiri dari dua lapisan oktahedral dan satu lapisan tetrahedral, misalnya monmorillonit, mika dan vermikulit, (3). mineral tipe 2:1:1, mineral yang merupakan jenis 2:1 dengan satu lapisan oktahedral tambahan yang tersusun berselang seling, misalnya klovit. Dalam kelompok mineral tersebut, monmorillonit adalah kelompok mineral yang paling menarik karena kemampuannya untuk mengembang (swelling) dan mempunyai kapasitas penukar ion yang tinggi sehingga mampu mengakomodasi kation antar lapisnya dalam jumlah besar (Ogawa, 1992 ; Wijaya 2000). Struktur montmorillonit dapat dilihat pada gambar 3.

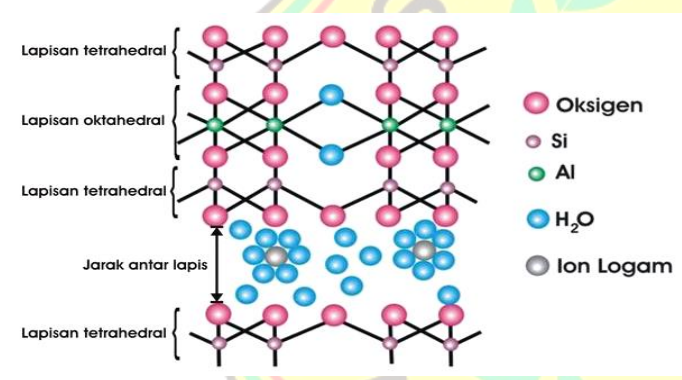

\section{Gambar 3. Struktur Montmorillonit}

Lempung bentonit merupakan partikelpartikel dengan sifat koloid yang tinggi, lempung plasis yang pertma kali ditemukan di Fort Benton (Wyoming, Amerika Serikat). Lempung bentonit mempunyai sifat yang khas yaitu mampu mengembang menjadi beberapa kali lipat dar volume awalnya bila ditempatkan dalam air (Grim, 1968). Lempung bentonit adalah jenis lempung yang tersusun dari mineral montmorillonit yang tidak murni, Kristal lempung bentonit berbentuk seperti lempeng dengan kisi menyerupai phirophilit dan setiap unit lapisnya memiliki muatan permukaan negatif. Lempung bentonit mempunyai warna yang beragam, tetapi biasanya kuning sampai kuning kehijau-hijauan. Dalam keadaan kering lempung bentonit berwarna krem dengan titik lebur berkisar $1330-1430^{\circ} \mathrm{C}$.
Kandungan montmorillonit dalam lempung bentonit biasanya melebihi $90 \%$, sedangkan menurut Grimshaw dan Searli (1960), struktur kimia monmorillonit secara umum dapat ditulis:

\begin{tabular}{|c|c|c|}
\hline $\begin{array}{c}\left(\mathrm{Al}^{1+}, \mathrm{Fe}^{3+}, \mathrm{Cr}^{3+}, \mathrm{Mn}^{3+}\right) \\
\text { kation group } \mathrm{A}\end{array}$ & $\begin{array}{l}\left(\mathrm{Al}_{y_{y}^{3+}}, \mathrm{Si}_{4 . \mathrm{r}^{4+}}\right) \\
\text { kation group } \mathrm{B}\end{array}$ & $\begin{array}{c}\mathrm{O}_{\mathrm{id}}(\mathrm{OH}) \\
\text { kation group C }\end{array}$ \\
\hline
\end{tabular}

Kation group A adalah kation yang terdapat dalam struktur oktahedral, kation group B adalah kation dalam struktur tetrahedral. Sedangkan anion group $\mathrm{C}$ terdiri dari oksigen dan hidroksil. Kation group D adalah kation yang terabsorbsi oleh monmorillonit dan dapat ditukar dengan ion lain.

\section{METODOLOGI PENELITIAN}

Tanah lempung alam yang telah dikeringkan kemudian digerus dan diayak. Lempung yang lolos 80 mesh dan tidak lolos 200 mesh digunakan untuk penelitian. Lempung ini kemudian dicuci dengan akuades, selanjutnya disaring dan dikeringkan dalam oven pada temperatur $110-120{ }^{\circ} \mathrm{C}$ selama 2 jam. Lempung ini digerus dan diayak dengan ayakan 80 mesh. Sampel ini digunakan untuk analisis gugus fungsi menggunakan metode spektroskopi infra red (IR) dan analisis kandungan mineralnya menggunakan metode difraksi sinar-X (XRD) serta analisis komposisi kimia senyawa penyusun lempung dengan metode X-Ray Fluoresence (XRF).

\section{HASIL DAN PEMBAHASAN}

Lempung alam umumnya ditemukan dalam bentuk campuran beberapa jenis lempung. Oleh karena itu aplikasi komersial lempung alam biasanya didasarkan pada dominansi satu jenis lempung tertentu dibandingkan jenis lempung yang lain. Bentonit misalnya, merupakan lempung alam dengan kandungan lempung jenis monmorillonit lebih dari $85 \%$ (Riyanto, 1994). Analisis kandungan mineral lempung alam dari Pacitan ini akan dilakukan dengan 3 cara yaitu berdasarkan hasil spektrofotometri inframerah dan analisis komposisi kimia senyawa penyusun lempung menggunakan difraksi sinar-X dan $X$ Ray Fluoresence. 


\section{Metoda Spektrofotometri Infrared (IR)}

Salah satu kajian mineralogi lempung adalah dengan spektroskopi inframerah. Spektrum serapan inframerah suatu mineral mempunyai pola yang khas. Spektrum serapan inframerah dapat digunakan untuk identifikasi mineral tersebut serta menunjukkan gugus fungsional utama di dalam struktur senyawa yang diidentifikasi. Analisis dengan spektroskopi inframerah dilakuan untuk mengetahui jenis vibrasi antara atom-atom dalam mineral lempung alam. Analisis dilakukan pada daerah bilangan gelombang $400-4000 \mathrm{~cm}^{-1}$ karena biasanya spektra yang karakteristik akan muncul pada daerah tersebut. Fungsi utama dari spektrometri infra merah adalah untuk mengenal struktur molekul khususnya gugus fungsional beserta lingkungannya. Metode pelet $\mathrm{KBr}$ paling luas digunakan untuk analisis infra merah bagi sampel padatan mineral lempung. Dilakukan dengan menumbuk sampel $(0,1-2 \%$ berat $)$ dengan $\mathrm{KBr}$, kemudian mencetaknya menjadi pelet transparan untuk kemudian dianalisis.Hasil analisis dengan spektrofotometer inframerah terhadap lempung alam disajikan dalam gambar 4 .

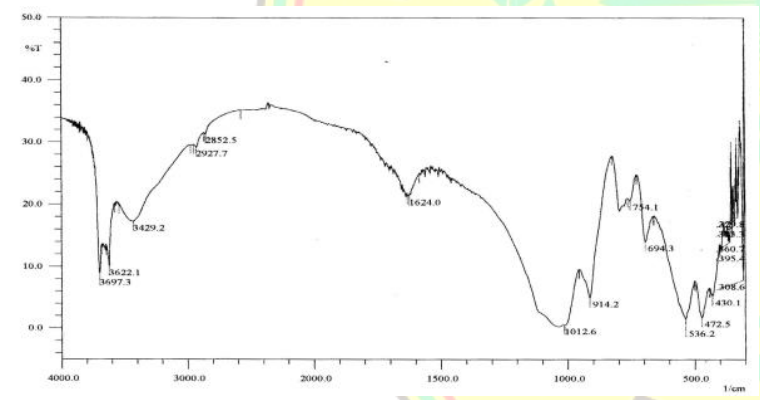

Gambar 4. Spektra inframerah lempung alam Tulakan Pacitan

Dari gambar 4 terlihat bahwa lempung alam mempunyai puncak serapan pada daerah bilangan gelombang 468,7; 538,1; 694,3; 754,1; 912,3; 1008,$7 ; 1629,7 ; 3431,1 ; 3622,1$ dan $3697,3 \mathrm{~cm}^{-1}$. Daerah 400-1200 $\mathrm{cm}^{-1}$ dinamakan juga daerah sidik jari (finge print region). Puncak-puncak yang muncul pada daerah ini anatara lain 1008,7; 912,$3 ; 754,1 ; 694,3 ; 538,1 ; 468,7 ;$ dan $426,2 \mathrm{~cm}$ ${ }^{1}$. Puncak serapan yang paling tajam pada daerah $1008,7 \mathrm{~cm}^{-1}$ adalah karakteristik vibrasi ulur dari Si-O. Hal ini diperkuat oleh Farmer dan Russell (1964) yang melaporkan bahwa puncak serapan untuk montmorillonit Wyoming (Amerika Serikat) muncul pada bilangan gelombang 1048 $\mathrm{cm}^{-1}$. Sedangkan Flanigen et.al (1971) menyatakan serapan kuat pada daerah 950 - 1250 $\mathrm{cm}^{-1}$ merupakan vibrasi ulur dari T-O (dimana T $=\mathrm{Si}$ atau $\mathrm{Al}$ ) yang melibatkan gerakan utama dari atom oksigen. Hal yang sama juga ditegaskan oleh Madejova (2002) yang mencatat puncak serapan khas Si-O dari montmorillonit, nontronit, hektorit dan saponit berturut-turut muncul pada bilangan gelombang 1030, 1019, 1012 dan 1009 $\mathrm{cm}^{-1}$.

Munculnya puncak pada bilangan gelombang $912,3 \mathrm{~cm}^{-1}$ merupakan vibrasi tekuk $\mathrm{OH}$ yang berikatan dengan kation. Serapan 754,1 $\mathrm{cm}^{-1}$ adalah serapan untuk vibrasi tekuk $\mathrm{Si}-\mathrm{O}$ yang tegak lurus sumbu optik. Sedangkan puncak pada bilangan gelombang 694,3 $\mathrm{cm}^{-1}$ merupakan vibrasi tekuk $\mathrm{Si}-\mathrm{O}$ yang sejajar dengan sumbu optik. Katti (2002) juga melaporkan bahwa vibrasi tekuk $\mathrm{OH}$ dengan kation terjadi pada daerah 918, 888 dan $847 \mathrm{~cm}^{-1}$, sedangkan puncak di bilangan gelombang $778 \mathrm{~cm}^{-1}$ adalah vibrasi tekuk Si-O yang tegak lurus dengan sumbu optik dan $671 \mathrm{~cm}^{-1}$ merupakan vibrasi tekuk Si-O yang sejajar dengan sumbu optik.

Vibrasi tekuk Si-O-Al (Al oktahedral) muncul pada bilangan gelombang $538,1 \mathrm{~cm}^{-1}$, sedangkan $468,7 \mathrm{~cm}^{-1}$ merupakan vibrasi tekuk Si-O-Si. Menurut Komadel (2003) vibrasi tekuk Si-O-Al terjadi pada daerah serapan $520 \mathrm{~cm}^{-1}$ yang mana merupakan pita yang sangat sensitif dengan kehadiran $\mathrm{Al}$ di lapis oktahedral sedangkan Madejova (2002) mengamati vibrasi tekuk Si-O-Al terjadi pada serapan $520 \mathrm{~cm}^{-1}$ dan vibrasi tekuk Si-O-Si pada bilangan gelombang $470 \mathrm{~cm}^{-1}$.

Adanya serapan pada daerah bilangan gelombang $1629,7 \mathrm{~cm}^{-1}$ merupakan vibrasi tekuk -OH dari molekul air terserap. Hal ini sampir sama dengan yang diamati oleh Grim (1968) dalam Darwanta (2002) yang menyatakan bahwa $\mathrm{H}_{2} \mathrm{O}$ yang terserap memberikan serapan pada daerah 3400 dan $1640 \mathrm{~cm}^{-1}$ yang sesuai dengan vibrasi dari $\mathrm{H}_{2} \mathrm{O}$. Menurut Katti (2002) bahwa serapan pada $1635 \mathrm{~cm}^{-1}$ adalah vibrasi tekuk $\mathrm{H}$ $\mathrm{O}-\mathrm{H}$. 
Munculnya serapan pada daerah bilangan gelombang 3697,3 dan 3622,1 menunjukkan adanya vibrasi ulur dari $-\mathrm{OH}$, sedangkan vibrasi pada $3431,1 \mathrm{~cm}^{-1}$ merupakan vibrasi $\mathrm{H}-\mathrm{O}-\mathrm{H}$ yang membentuk ikatan hidrogen dengan air. Hal ini juga ditegaskan oleh Madejova (2002) bahwa munculnya puncak pada bilangan gelombang 3669; 3653 dan $3620 \mathrm{~cm}^{-1}$ merupakan vibrasi ulur - $\mathrm{OH}$ dari silanol atau yang terdapat diantara lembaran tetrahedral dengan oktahedral, begitu juga dengan Katti (2002) melaporkan serapan pada $3634 \mathrm{~cm}^{-1}$ adalah vibrasi tekuk O-H sedangkan pada bilangan gelombang $3433 \mathrm{~cm}^{-1}$ merupakan vibrasi $\mathrm{H}-\mathrm{O}-\mathrm{H}$ yang membentuk ikatan hidrogen dengan air. Dapat disimpulkan bahwa kandungan utama lempung alam Tulakan Pacitan adalah montmorilonit dengan melihat adanya kesesuaian puncak-puncak pada spektra inframerah lempung/alam Tulakan Pacitan dengan lempung montmorilonit hasil peneliti lain.

\section{Metode $X$-Ray Difraction (XRD)}

Pada umumnya lempung alam terdiri dari campuran berbagai macam mineral lempung yang bercampur bersama-sama. Analisis lempung alam dengan difraksi sinar-X dilakukan untuk mengetahui jenis mineral penyusun lempung alam yang ditunjukkan oleh munculnya puncak pada daerah $2 \theta$ dan tingkat kristalinitas struktur komponen penyususun lempung yang ditunjukkan oleh tinggi atau rendahnya intensitas puncak. Pola difraksi sinar-X dari lempung alam ditampilkan pada difraktogram gambar 5.

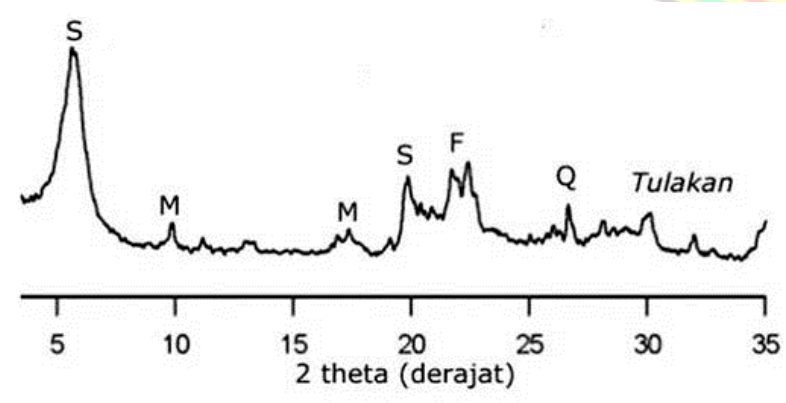

Gambar 5. Spektra difraksi sinar-X lempung Tulakan Pacitan.

( $\mathbf{S}=$ Smectite, $\mathbf{C h}=$ Klorite, $\mathbf{M}=$ Mika, $\mathbf{F}=$ Feldspar, Q = Kuarsa)
Hasil analisis difraksi sinar-X dapat diidentifikasi puncak-puncak difraktogram dari lempung sesuai jenis mineralnya. Dengan membandingkan harga $d_{h k l}$ yang ada pada lempung alam dengan harga $\mathrm{d}_{\mathrm{hkl}}$ mineral yang terdapat dalam Mineral Powder Diffraction File maka mineral-mineral penyusun lempung alam yang dipakai pada penelitian ini dapat diketahui.

Pada difragtogram terlihat adanya puncak utama pada daerah $2 \theta=5,70^{\circ}\left(\mathrm{d}_{001}=15,48 \AA\right)$ yang merupakan puncak $\mathrm{d}_{001}$ untuk mineral smectit jenis montmorillonit dan juga muncul pada daerah $2 \theta=20,02^{\circ} \quad\left(\mathrm{d}_{001}=4,43 \quad \AA\right)$. Munculnya puncak pada daerah $2 \theta=9,85^{\circ}$ dan $2 \theta=17,73^{\circ}$ menunjukkan adanya mika yang diduga berjumlah sedikit karena intensitasnya rendah. Adanya puncak pada daerah $2 \theta=22,20^{\circ}$ dan $2 \theta=26,64^{\circ}$ berturut-turut merupakan puncak dari mineral feldspar dan kuarsa dengan intensitas lebih rendah jika dibandingkan dengan intensitas smectit, sehingga dapat disimpulkan bahwa lempung alam Tulakan Pacitan mengandung mineral montmorillonit sebagai komponen utama.

\section{Metode X-Ray Fluoresence (XRF)}

Karakterisasi berikutnya yaitu dengan metoda fluoresensi sinar-X untuk menentukan komposisi kimia senyawa penyusun lempung alam. Komposisi kimia hasil analisa ditampilkan pada tabel 1. Berdasarkan hasil analisa dengan metoda fluoresensi sinar-X dari tabel 1 diperoleh data persentase komposisi $\mathrm{SiO}_{2}$ adalah sebesar $58,810 \%$ dan $\mathrm{Al}_{2} \mathrm{O}_{3}$ sebesar $13,510 \%$, sehingga diduga bahwa komponen utama penyusun lempung alam Tulakan Pacitan adalah mineral silikat aluminat.

Tabel 1. Komposisi kimia lempung alam Tulakan Pacitan *)

\begin{tabular}{|c|c|}
\hline Kelimpahan senyawa & Komposisi (\% berat) \\
\hline $\mathrm{SiO}_{2}$ & 58,810 \\
\hline $\mathrm{Al}_{2} \mathrm{O}_{3}$ & 13,510 \\
\hline $\mathrm{MgO}$ & 3,090 \\
\hline $\mathrm{CaO}$ & 2,733 \\
\hline $\mathrm{Fe}_{2} \mathrm{O}_{3}$ & 2,130 \\
\hline $\mathrm{K}_{2} \mathrm{O}$ & 0,549 \\
\hline
\end{tabular}




\begin{tabular}{|c|c|}
\hline Kelimpahan senyawa & Komposisi (\% berat) \\
\hline $\mathrm{TiO}_{2}$ & 0,244 \\
\hline $\mathrm{Na}_{2} \mathrm{O}$ & 0,130 \\
\hline $\mathrm{P}_{2} \mathrm{O}_{5}$ & 0,072 \\
\hline $\mathrm{F}$ & $<0,050$ \\
\hline $\mathrm{MnO}$ & 0,017 \\
\hline $\mathrm{SO}_{2}$ & 0,010 \\
\hline $\mathrm{Cl}$ & $<0,002$ \\
\hline $\mathrm{LOI}$ & 18,350 \\
\hline
\end{tabular}

*) komposisi senyawa diukur menggunakan XRay Fluoresence

Berdasarkan analisa dengan metoda difraksi sinar-X diperoleh informasi komponen penyusun lempung alam Tulakan Pacitan terdiri dari mineral montmorilonit, mika, feldspar dan kuarsa, dimana mineral montmorilonit sebagai komponen utama penyusun lempung alam Tulakan Pacitan. Data komposisi kimia hasil analisis dengan metoda fluoresebsi sinar-X, diduga bahwa komponen utama penyusun lempung alam Tulakan Pacitan adalah mineral silika alumina. Dari hasil identifikasi dengan menggunakan metoda difraksi sinar-X dan fluoresensi sinar-X dapat disimpulkan bahwa komponen utama penyusun lempung alam Tulakan Pacitan adalah mineral montmorillonit.

\section{KESIMPULAN}

Dari hasil analisis spektroskopi infrared dapat disimpulkan gugus-gugus fungsional yang terdapat dalam lempung Pacitan antara lain Si-O, -OH, Si-O-Al dan Si-O-Si. Sedangkan jenis mineralnya dari hasil analisis X-Ray Difraction dan

Smectite, Klorite, Mika, Feldspar dan Kuarsa yang didominasi oleh mineral smectite jenis montmorillonit sebagai komponen utama.

\section{DAFTAR PUSTAKA}

Darwanta, 2002, "Sintesis dan Karakterisasi Lempung Terpilar-Al Serta Aplikasinya Sebagai Katalis Hidrorengkah Fraksi Berat Minyak Bumi”, Tesis S-2, Universitas Yogyakarta.
Flanigen, E.M., Khatami, H., 1971, "Infrared Structural Studies of ZeoliteFramework, Molecullar Sieve Zeolite-I", American Society Adv. In Chemistry Series No. 101, Washington, 201-226.

Grim R.E., 1968", Clay Mineralogy", second Edition, Me Graw Hill Book Company, New York

Katti,K., and Katti D., 2001, "Effect of ClayWater Interactions on Swelling in Montmorillonite Clay", Departement of Civil Engineering and Construction North Dakota State University, Fargo.

Komadel, P., 2003, "Chemically Modified smectites", Slovac Academy of Sciences, Slovakia, Clay Mineral, 38, 127 -138.

Madejova, J., 2003, "FTIR Techniques in Clays Mineral Studies", Slovac Academy of Sciences, Slovakia, 31, $1-10$.

Mahida, U. N. 1984. "Pencemaran Air dan Pemanfaatan Limbah Industri". CV Rajawali, Jakarta.

Ogawa, M. and Kuroda, K., 1997, "Preparation of Inorganic Nanocomposites through Intercalation of Organoammonium Ions into Layered Silicates", Bull. Chem. Soc. Jpn., 70, 2593-2618.

Pinnavaia, T.J., 1983, "Intercalated Clay Catalyst", Science, $220-365$.

Pinnavaia, T.J., Galarneau, A. H., and Barodawalla, A. F., 1998, "Porous Clay Heterostructure by Gallery Templated Synthesis", United State Patent, 5, 834-391.

Riyanto, A., 1994, " Bahan Galian Industri Bentonit", Direktoral Jendral Pertambangan Umum, Pusat Penelitian dan Pengembangan Teknologi Mineral, Bandung.

Wijaya, Karna, 2000, "Sintesis Lempung Monmorilonit Terpilar Berbahan Baku Bentonit Alam Indonesia dan Aplikasinya Sebagai Katalis, Bahan Foto-Fungsional dan Adsorben”, Universitas Gadjah Mada, Yogyakarta. 